Research Paper

\title{
The neuroleptic drug pimozide inhibits stem-like cell maintenance and tumorigenicity in hepatocellular carcinoma
}

\author{
Jia-Jie Chen ${ }^{1,3,4, *}$, Nan Cai ${ }^{1,3, *}$, Guan-Zhong Chen ${ }^{1,2, *}$, Chang-Chang Jia ${ }^{1,3}$, Dong-Bo \\ Qiu ${ }^{2,3}$, Cong Du ${ }^{2,3}$, Wei Liu' ${ }^{1,2}$, Yang Yang ${ }^{1}$, Zi-Jie Long ${ }^{4}$ and Qi Zhang ${ }^{1,2,3}$ \\ ${ }^{1}$ Organ Transplantation Center, The Third Affiliated Hospital of Sun Yat-Sen University, Guangzhou, People's Republic of \\ China \\ ${ }^{2}$ Guangdong Provincial Key Laboratory of Liver Disease Research, The Third Affiliated Hospital of Sun Yat-Sen University, \\ Guangzhou, People's Republic of China \\ ${ }^{3}$ Vaccine Research Institute of Sun Yat-Sen University, The Third Affiliated Hospital of Sun Yat-Sen University, Guangzhou, \\ People's Republic of China \\ ${ }^{4}$ Department of Hematology, The Third Affiliated Hospital, Sun Yat-Sen University, Guangzhou, People's Republic of China \\ * These authors have contributed equally to this work \\ Correspondence to: Qi Zhang, email: keekee77@126.com
}

Zi-Jie Long, email: longzij@mail.sysu.edu.cn

Keywords: pimozide, hepatic cancer stem-like cells, self-renewal, STAT3 signaling, STAT3 inhibitor

Received: February 11, $2015 \quad$ Accepted: May 13, $2015 \quad$ Published: May 27, 2015

\section{ABSTRACT}

Drug repurposing is currently an important approach for accelerating drug discovery and development for clinical use. Hepatocellular carcinoma (HCC) presents drug resistance to chemotherapy, and the prognosis is poor due to the existence of liver cancer stem-like cells. In this study, we investigated the effect of the neuroleptic agent pimozide to inhibit stem-like cell maintenance and tumorigenicity in HCC. Our results showed that pimozide functioned as an anti-cancer drug in HCC cells or stem-like cells. Pimozide inhibited cell proliferation and sphere formation capacities in HCC cells by inducing G0/G1 phase cell cycle arrest, as well as inhibited HCC cell migration. Surprisingly, pimozide inhibited the maintenance and tumorigenicity of HCC stem-like cells, particularly the side population (SP) or CD133-positive cells, as evaluated by colony formation, sphere formation and transwell migration assays. Furthermore, pimozide was found to suppress STAT3 activity in HCC cells by attenuating STAT3-dependent luciferase activity and down-regulating the transcription levels of downstream genes of STAT3 signaling. Moreover, pimozide reversed the stem-like cell tumorigenic phenotypes induced by IL-6 treatment in HCC cells. Further, the antitumor effect of pimozide was also proved in the nude mice HCC xenograft model. In short, the anti-psychotic agent pimozide may act as a novel potential anti-tumor agent in treating advanced HCC.

\section{INTRODUCTION}

New advances in drug discovery and development, to make pharmaceutical research more predictable and reliable are urgently needed [1]. One of the most important approaches is drug repurposing, in which new applications for existing or abandoned pharmacotherapies are investigated $[2,3]$. In cancer therapy, this technique has achieved affordable results, with new uses found for existing drugs [4]. For example, metformin is the 
most widely used anti-diabetic drug; however, this drug can also inhibit cancer cell growth in vitro and in vivo, functioning as an anti-cancer drug [5, 6]. Disulfiram, a drug that is widely used to control alcoholism, also suppresses the self-renewal of glioblastoma and overrides resistance to temozolomide [7]. Furthermore, the use of imatinib (Gleevec), a drug that was originally developed to treat chronic myelogenous leukaemia, has been expanded to treat several malignancies due to its targeting of similar signaling pathways [8], such as those in gastrointestinal stromal tumors [9] and colorectal cancers [10]. Consequently, finding new uses for existing drugs represents an effective strategy for developing novel pharmacotherapies to treat cancer cells.

Hepatocellular carcinoma (HCC) is one of the most common cancers worldwide and is a frequent cause of cancer-related deaths [11]. HCC patients typically have a relatively poor prognosis because most patients are at an advanced stage at the time of diagnosis and few effective therapeutic options are available for this advanced disease. Moreover, HCC cells are often refractory to standard chemotherapy and resistant to radiotherapy [12]. Recurrence or metastasis is quite common in patients, even in those patients undergoing liver cancer resection, and the survival rate is only $30 \%$ to $40 \%$ at 5 years postoperatively [13]. The existence of tumor-initiating cells or cancer stem-like/stem cells accounts partly for the chemo-resistance observed in HCC $[14,15]$. Extensive research over the past decade has identified several specific cellular signaling pathways that are affected in chemorefractory liver cancer, such as signal transducer and activator of transcription 3 (STAT3), NOTCH, hedgehog and transforming growth factor-beta (TGF- $\beta$ ), which are involved in the self-renewal, differentiation and survival of HCC cells [15-18]. Previous studies have shown that the inhibition of these various signaling pathways via targeted therapy with small molecule drugs appears to be a promising approach for the treatment of $\operatorname{HCC}[18,19]$. Therefore, the screening of existing drugs that potentially target specific important signaling pathways in HCC is of prime importance for developing novel and effective pharmacotherapies for treating advanced HCC.

Pimozide is an FDA-approved neuroleptic drug that belongs to the diphenylpiperidine class of drugs and that is commonly used to treat Tourette syndrome and schizophrenia [20]. Previous studies have shown that pimozide is efficacious in the treatment of carcinomas and leukaemias, such as melanoma [21], breast cancer [22], chronic myelogenous leukaemia [23] and acute myelogenous leukaemia induced by FLT3 mutations [24]. The neuroleptic agent pimozide inhibited the proliferation of the human breast cancer cell line MCF7 [22] and enhanced the cell death response of MCF-7 cells to gamma-radiation treatment [25]. Furthermore, pimozide suppressed the self-renewal capacity of chronic myelogenous leukaemia cells by inhibiting the activity of the cellular transcription factor STAT5 [23]. However, the effect of pimozide on HCC cells or stem-like cells and its molecular mechanisms have not yet been fully determined.

The aim of this study was to investigate the inhibiting effects of pimozide on HCC cells and stemlike cells. The results showed that pimozide inhibited cell proliferation, migration, colony formation and sphere formation in HCC cells as well as stem-like cells through suppressing STAT3 activity. To our surprise, pimozide reversed the stem-like cell tumorigenic phenotypes induced by IL- 6 addition. Furthermore, pimozide reduced the tumour burden in the nude mice xenograft model. Thus, the anti-psychotic agent pimozide may act as a potential anti-tumor therapeutic drug for HCC treatment, providing a novel therapeutic agent against advanced HCC.

\section{RESULTS}

\section{Pimozide inhibits HCC cell proliferation in dose- and time-dependent manners by inducing G0/G1 phase cell cycle arrest}

First, the anti-proliferative effect of the neuroleptic drug pimozide in HCC cells was detected using MTT assay. MHCC-97L, Hep 3B, Hep G2 and Huh7 cells were exposed to a series of concentrations $(0,1,5,10$, and 15 $\mu \mathrm{M}$ ) of pimozide for 24, 48 and $72 \mathrm{~h}$. As shown in Figure 1A, pimozide inhibited the proliferation of these 4 cell lines in both a dose- and time-dependent manner. The IC50 values at 24, 48 and $72 \mathrm{~h}$ were $21.57 \pm 3.16,15.97 \pm$ 0.16 and $6.15 \pm 0.48 \mu \mathrm{M}$ for MHCC-97L; $44.37 \pm 20.45$, $5.29 \pm 1.09$ and $1.81 \pm 0.51 \mu \mathrm{M}$ for Hep $3 \mathrm{~B} ; 11.43 \pm 0.55$, $3.96 \pm 0.62$ and $1.14 \pm 0.27 \mu \mathrm{M}$ for Hep G2; and 20.87 $\pm 1.54,20.23 \pm 3.31$ and $8.44 \pm 0.91 \mu \mathrm{M}$ for Huh7 cells, respectively. Next, we examined the effect of pimozide on HCC cells using CFSE staining. The data showed that the specific regions of CFSE staining in MHCC-97L and Hep $3 \mathrm{~B}$ cells treated with pimozide for $48 \mathrm{~h}$ were greater than that of the control $(p<0.01)$ (Figure 1B).

To determine whether pimozide could induce cell cycle arrest, we analysed the effect of pimozide on cell cycle distribution using PI staining. After MHCC-97L and Hep 3B cells were treated with pimozide for $24 \mathrm{~h}$, the percentage of cells in the G0/G1 phase increased significantly compared to the control $(p<0.01$; Figure $1 \mathrm{C})$. Following treatment with $10 \mu \mathrm{M}$ pimozide, $\mathrm{MHCC}$ 97L cells had a significant increase in the percentage of G0/G1 phase cells, from $51.59 \pm 3.49 \%$ to $76.95 \pm 2.98 \%$. Further examination of molecular markers associated with G0/G1 phase arrest showed remarkable increase in the p21 and p27 levels, and a decrease in the cyclin D1 level (Figure 1D), which is consistent with the G1 arrest phenomenon observed by flow cytometric analysis. These results implied that the neuroleptic drug pimozide represented a potential therapeutic index for treating HCC. 
A
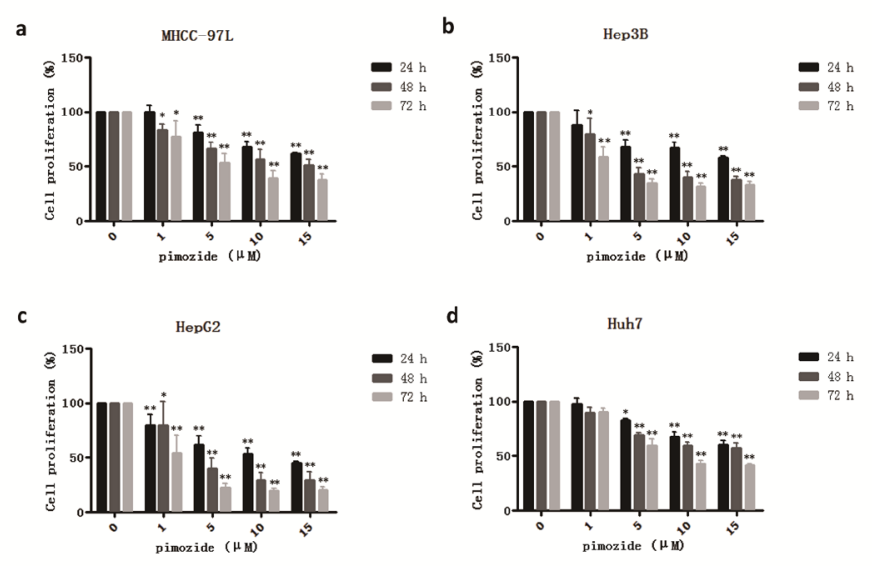

B

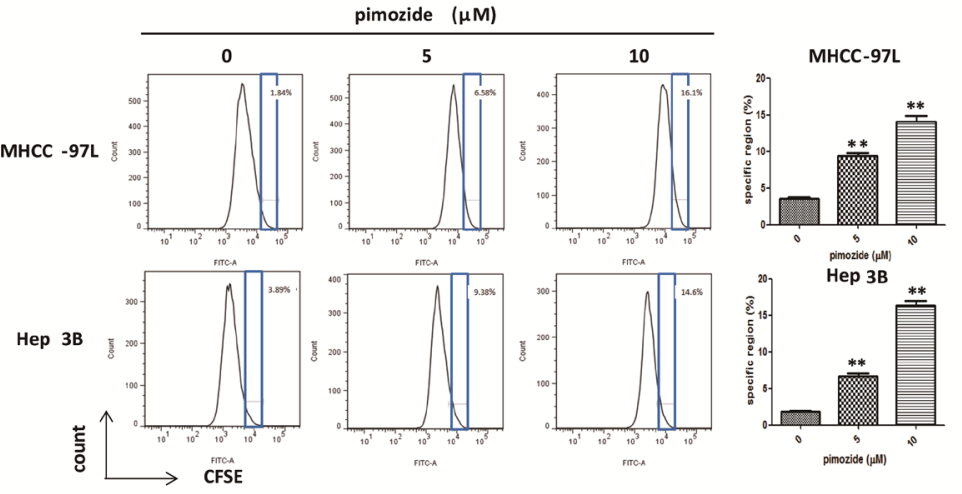

C

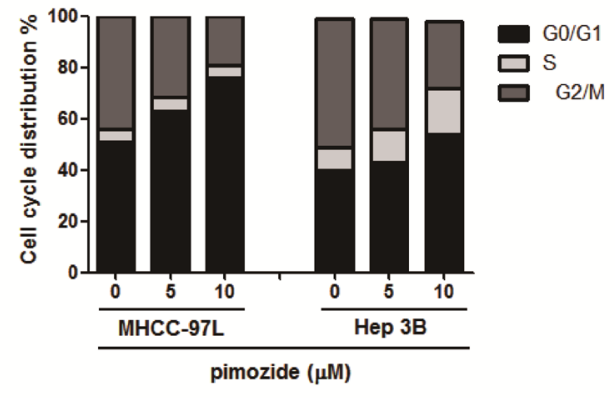

D

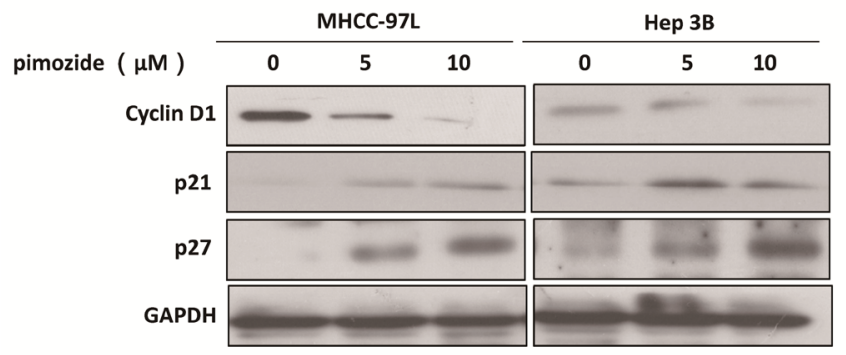

Figure 1: The neuroleptic drug pimozide inhibits HCC cell proliferation in dose- and time-dependent manners by inducing G0/G1 phase cell cycle arrest. A. MHCC-97L (a), Hep 3B (b), Hep G2 (c) and Huh7 (d) cells were treated with various concentrations of pimozide for various times, and cell viability was determined by MTT assay. B. Then, the cells were subjected to flow cytometric analysis to determine the level of CFSE staining. C. The cells stained with PI were subjected to flow cytometric analysis to determine the cell distributions at each phase of the cell cycle. The results are shown as the mean values \pm SD of 3 independent experiments. ${ }^{*} p<0.05,{ }^{*} p<0.01$, compared with the control. D. Western blot analysis of the expression of cell cycle-related genes. Cell extracts were probed with antibodies against p21, p27, Cyclin D1 and GAPDH (loading control) as indicated. 


\section{Pimozide inhibits the self-renewal capacity of HCC cells}

Furthermore, we examined whether pimozide inhibited the self-renewal capacity of HCC cells. The colony and sphere formation assays showed that pimozide inhibited the self-renewal capacity of the HCC cell lines MHCC-97L and Hep 3B in a dose-dependent manner (Figure 2A-2D). Following treatment with $5 \mu \mathrm{M}$ pimozide for one week, MHCC-97L cells showed a decrease of 93.0 $\pm 2.65 \%$ in the colony numbers and a significant decrease in the sphere numbers. Similar results were observed in the Hep 3B cells.

The expression levels of self-renewal-related proteins were measured by western blot analysis to delineate the mechanism of pimozide activity (Figure 2E). $\mathrm{HCC}$ cells treated with pimozide for $48 \mathrm{~h}$ demonstrated significantly down-regulated expression of stemness protein, including Bmi-1, c-Myc and Nanog, but showed no significant change in OCT $3 / 4$ expression. In addition, RT-PCR assay showed that pimozide down-regulated transcriptional expression levels of Bmil and Nanog of HCC cells in a dose-dependent manner (Figure 2F). These results indicated that pimozide inhibited the self-renewal capacity of HCC cells by suppressing the expression of key stemness transcription factors Bmi-1, c-Myc and Nanog.

\section{Pimozide suppresses HCC cell migration}

As shown in Figure 3A and 3B, all of MHCC-97L, MHCC-97H and Hep 3B cells demonstrated reduced cell migration capacity after treatment with 5 and 10 $\mu \mathrm{M}$ pimozide compared to the control, as evaluated by transwell migration assay. The ability to migrate in chambers without a matrix was significantly reduced to $29.03 \pm 9.68 \%$ and $25.80 \pm 5.07 \%$ respectively in MHCC97L and MHCC-97H cells, after $5 \mu \mathrm{M}$ pimozide treatment (Figure 3A and 3B). Furthermore, Hep 3B cells treated with $5 \mu \mathrm{M}$ pimozide had a decrease of $66.5 \pm 2.43 \%$ of migrated cells compared to the control $(p<0.01$; Figure $3 \mathrm{~A}$ and $3 \mathrm{~B})$.

In order to detect the toxicity or side effects of pimozide, apoptotic cell percentage was measured by Annexin-V-FITC/PI double staining assay. The result showed that pimozide did not induce obvious apoptosis of HCC cells (Supplemental Figure 2A and 2B). Moreover, epithelial-mesenchymal transition (EMT) has gained increasing attention due to its importance in the acquisition of metastatic and drug-resistant potential during tumour progression [28]. Here, we assessed whether pimozide inhibited HCC cell migration via the EMT process. Western blot analysis was performed to validate the expression of the EMT markers E-cadherin, N-cadherin and vimentin. Pimozide down-regulated the expression levels of N-cadherin and vimentin and up-regulated the expression level of E-cadherin in a dose-dependent manner, suggesting that pimozide inhibited HCC cell migration by suppressing EMT markers expression (Figure 3C).

\section{Pimozide inhibits the self-renewal and migration capacities of SP HCC cells}

Cancer stem and stem-like cells play a pivotal role in carcinogenesis and tumour recurrence. A previous study showed that SP cells were a minor subset of cancer stemlike cells in the HCC cell line MHCC-97L [29]. To clarify the effect of pimozide on HCC stem-like cells, the SP fraction in MHCC-97L cells was sorted by flow cytometric analysis (Figure 4A) and displayed respectively resistant to fluorouracil (5-FU), cisplatin (Cis) and doxorubicin (Dox) (Supplemental Figure 1A). Pimozide suppressed the colony and sphere formation capacities in these SP cells compared to the control (Figure 4B and 4C). MHCC$97 \mathrm{~L}$ SP cells showed a significant $62 \%$ reduction in colony numbers and an $83 \%$ decrease in sphere numbers after treatment with $5 \mu \mathrm{M}$ pimozide. Figure 4D showed that pimozide treatment inhibited SP cell migration, as evaluated by transwell migration assay. These data suggested that pimozide has the potential to inhibit the self-renewal and migration capacities of HCC SP cells in vitro.

\section{Pimozide inhibits the self-renewal and migration capacities of CD133-positive HCC cells}

CD133 is a candidate marker for enriching cancer stem or progenitor cells in HCC [30]. Pimozide obviously reduced CD133-positive populations in MHCC-97L cell lines at the concentration of $10 \mu \mathrm{M}$ (Supplemental Figure 3). Also, we further tested whether pimozide showed an anti-proliferative effect on CD133-positive MHCC-97L cells. As shown in Figure 5A and 5B, CD133-positive fraction was obtained by fluorescence-activated cell sorting, and showed resistance to 5-FU, Cis and Dox (Supplemental Figure 1B). Colony and sphere formation assays showed that pimozide inhibited the self-renewal capacity of CD133-positive MHCC-97L cells (Figure 5B and $5 \mathrm{C}$ ). Following treatment with $5 \mu \mathrm{M}$ pimozide for one week, CD133-positive cells showed a decrease of 94.0 $\pm 1.0 \%$ in colony numbers and a significant decrease in sphere numbers. Similar results were shown in CD133negative cells. Furthermore, CD133-positive cells treated with $10 \mu \mathrm{M}$ pimozide had a significant decrease in migrated cells compared to the control ( $p<0.01$; Figure 5D). These results indicated that pimozide could inhibit the self-renewal and migration capacities of CD133positive HCC cells in vitro. 
A

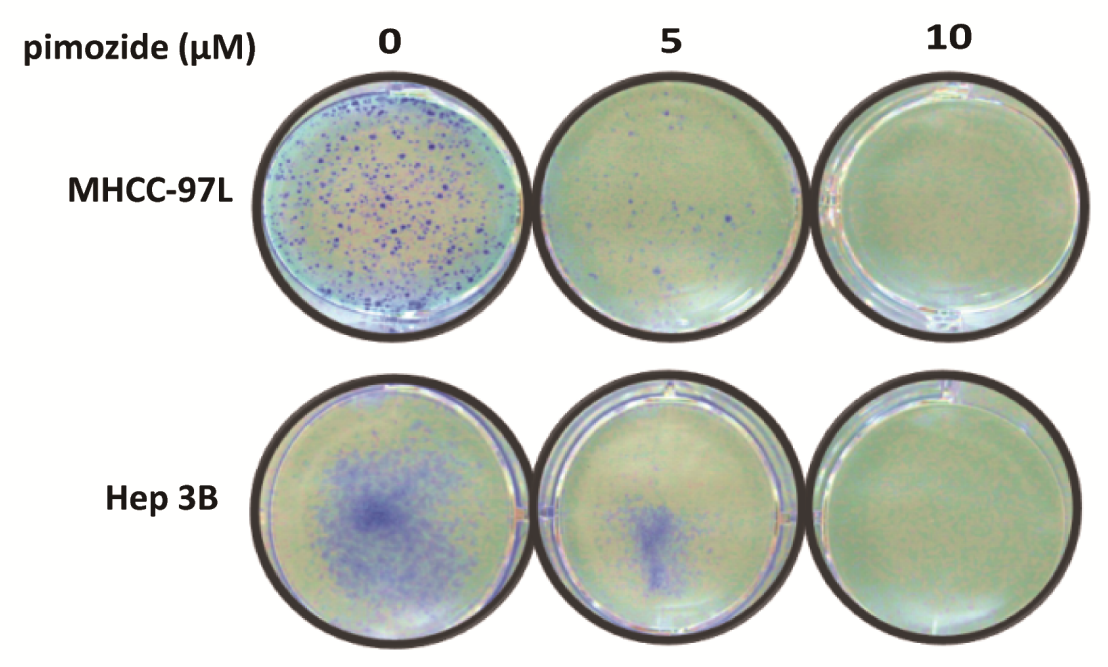

B (a)

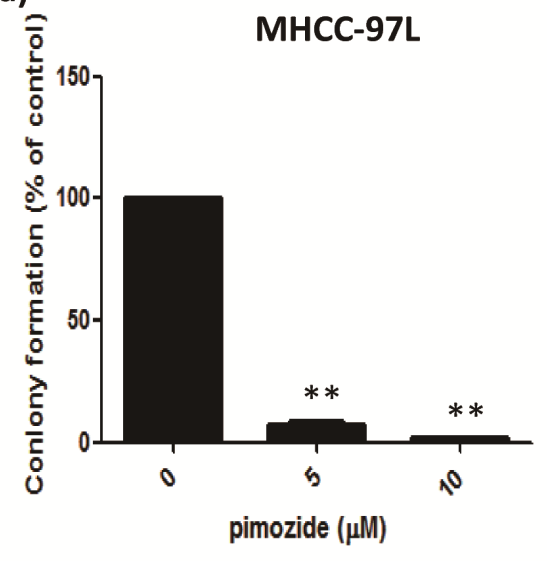

(b)

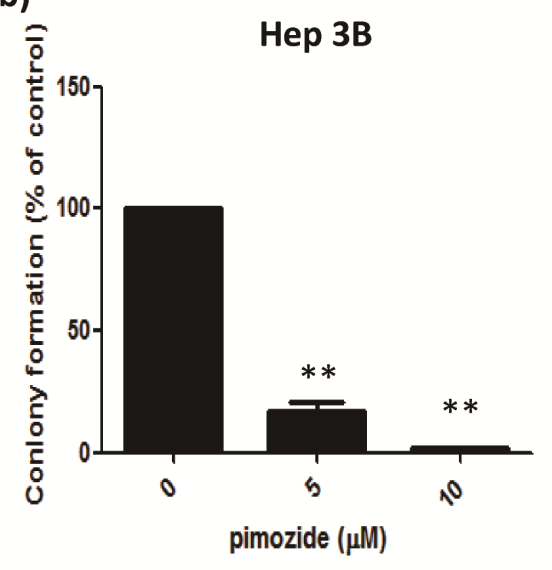

C

pimozide $(\mu \mathrm{M})$ 0 5 10
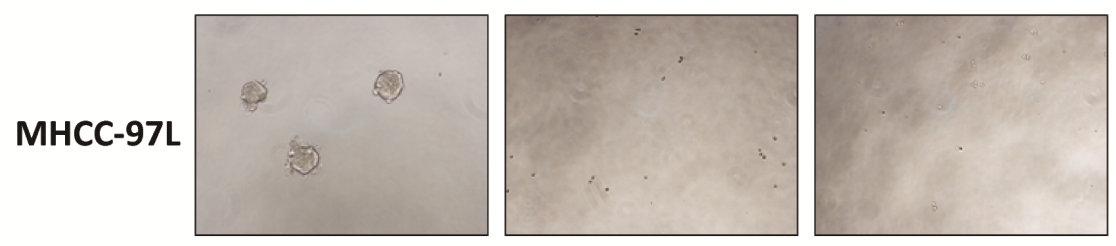

Нер 3В
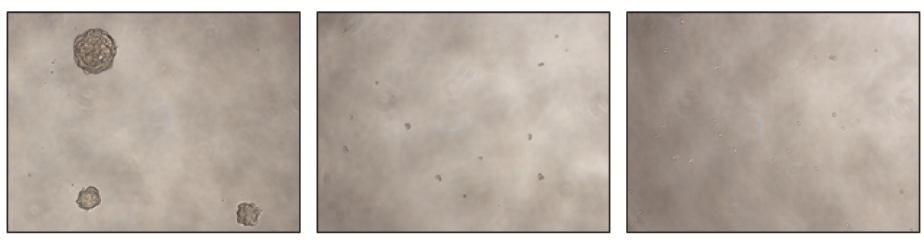
D
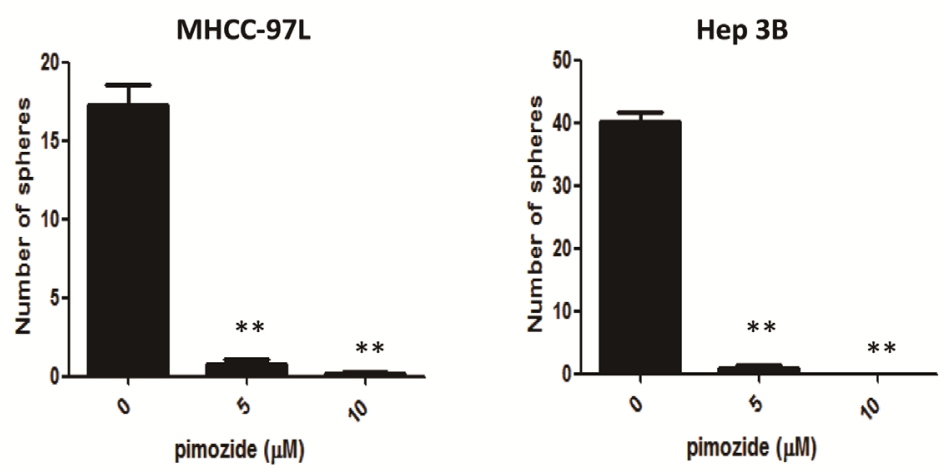

$\mathbf{E}$
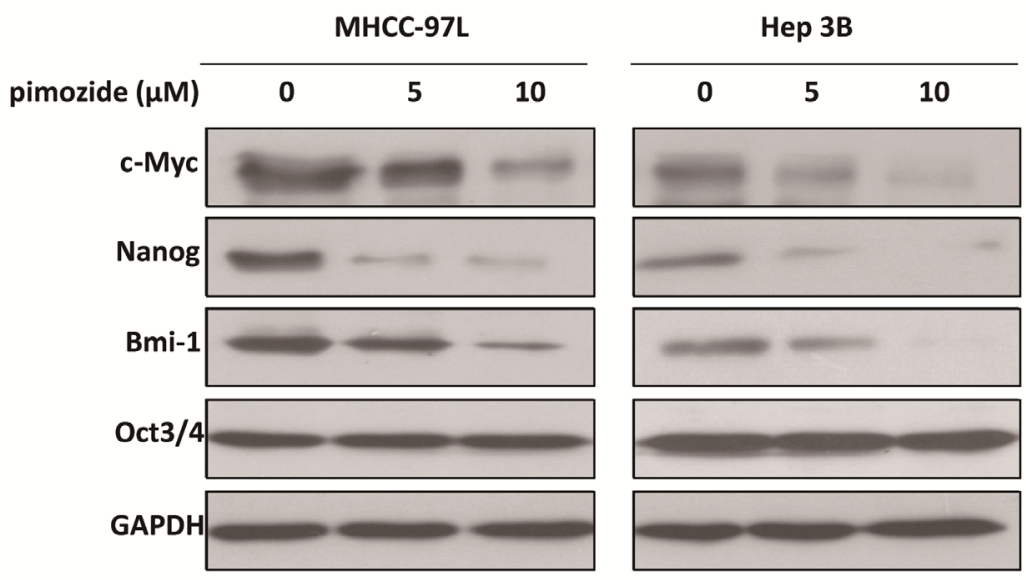

$\mathbf{F}$

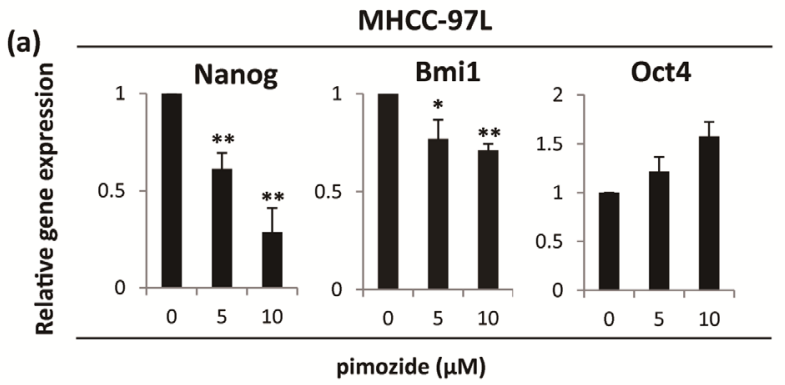

(b)

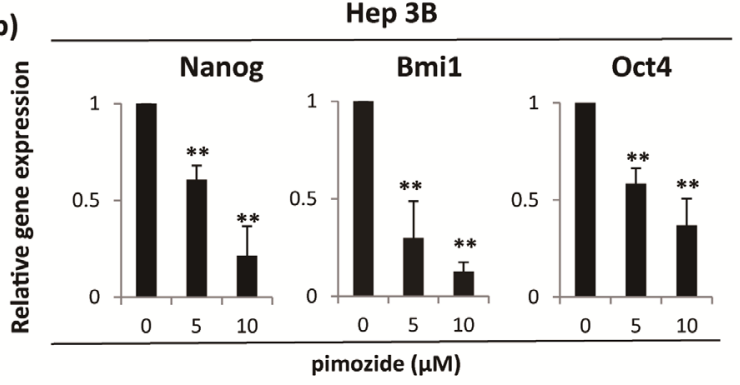

Figure 2: Pimozide inhibits the self-renewal capacity of HCC cells. MHCC-97L and Hep 3B cells were treated with pimozide at the indicated concentrations, incubated for extra 10-14 day and then subjected to colony formation assay. Images were taken at a magnification of $100 \times \mathbf{A}$. The numbers of colonies were counted after staining with crystal violet and the histogram indicated the number of colonies. The results are from 3 independent transfection experiments $(\mathbf{B})$. (C \& D). Sphere formation assay of HCC cells treated with pimozide. The spheres were imaged under a light microscope (magnification, 100×), and the statistical results are shown. E. Western blot analysis of the expression of self-renewal genes. Cell extracts were probed with antibodies against c-Myc, Bmil, Nanog, Oct3/4 and GAPDH. F. MHCC-97L and Hep 3B cells were incubated with the indicated doses of pimozide for 48h before subjected to RT-PCR to detect the expression of the self-renewal genes Bmil, Nanog and Oct4. ${ }^{*} p<0.05,{ }^{* *} p<0.01$, compared with the control. 
A

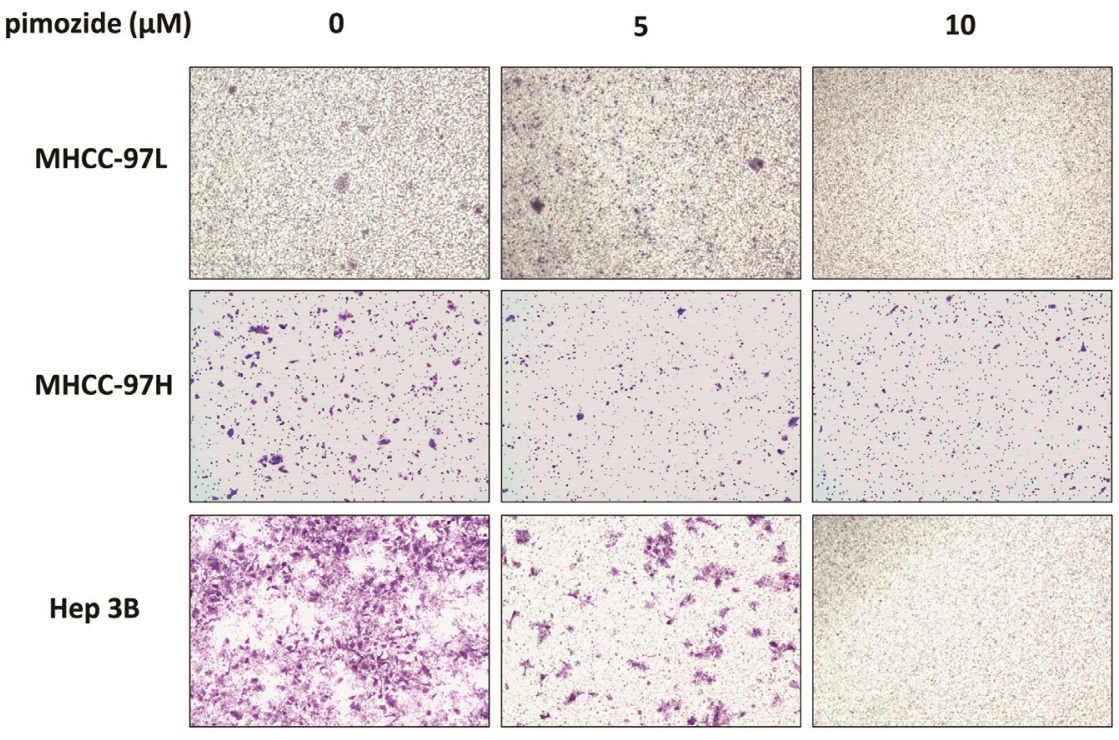

B

(a)

(b)
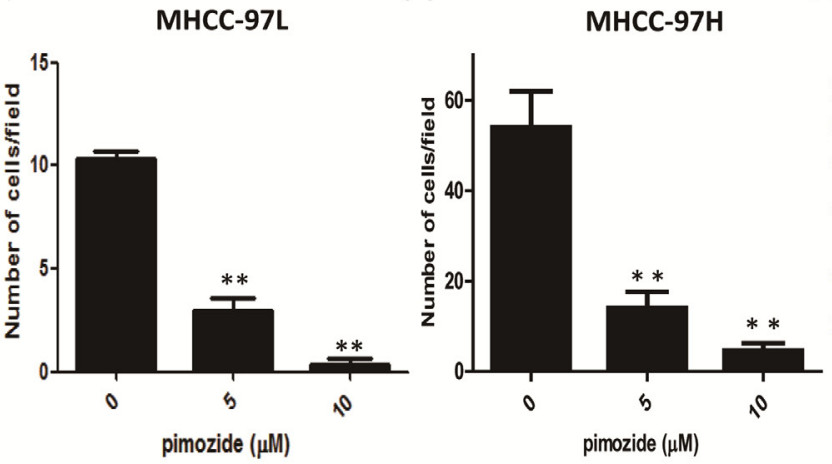

(c)

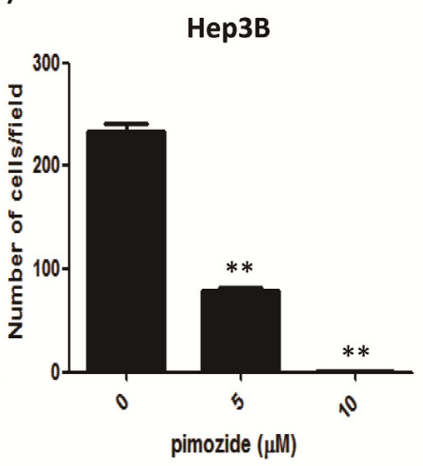

C

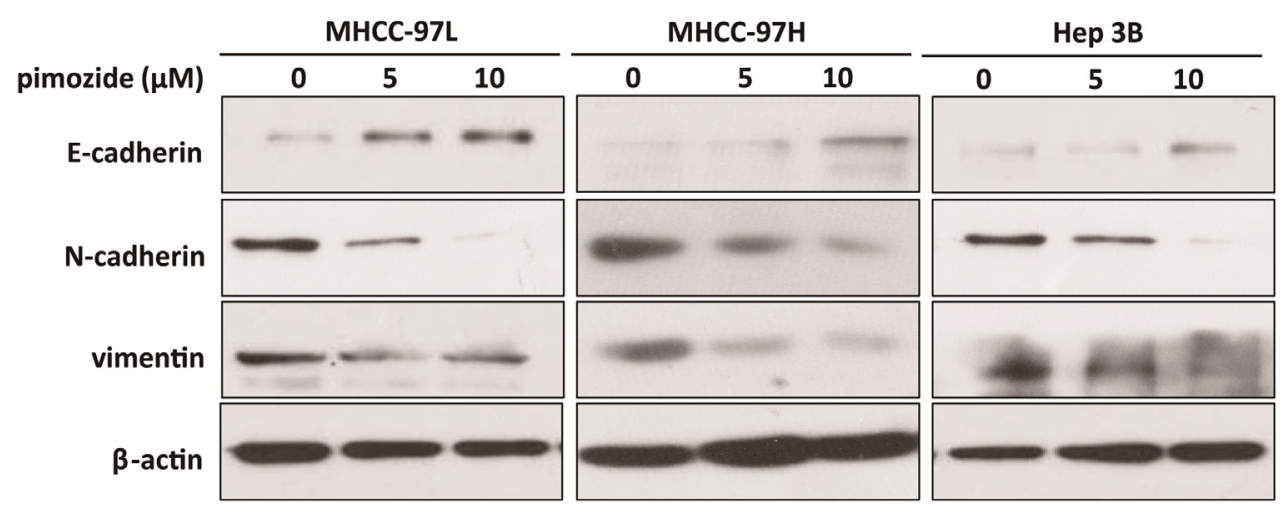

Figure 3: Pimozide suppresses HCC cell migration. Transwell migration assays of HCC cells treated with pimozide for $48 \mathrm{~h}$. A. Images shown at a magnification of $100 \times$. B. The data are summarized from 3 independent experiments, ${ }^{*} p<0.05,{ }^{* *} p<0.01$, compared to the control. C. Western blotting analysis of the expression of EMT-related markers. Cell extracts were probed with antibodies directed against E-cadherin, $\mathrm{N}$-cadherin, vimentin and $\beta$-actin (loading control) as indicated. 


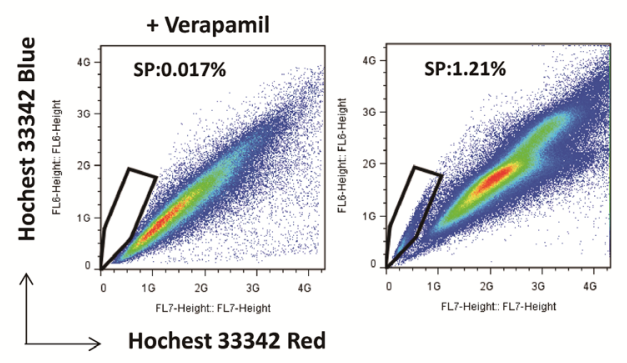

B

(a)

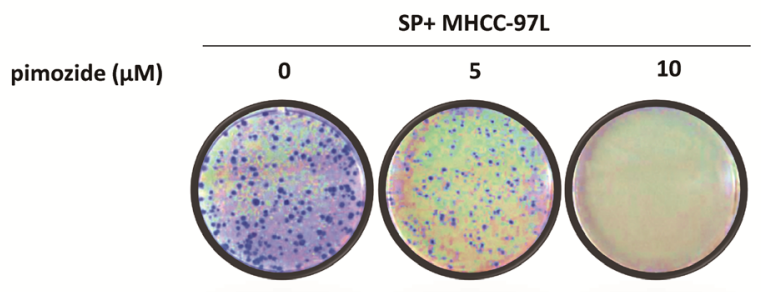

C

(a)

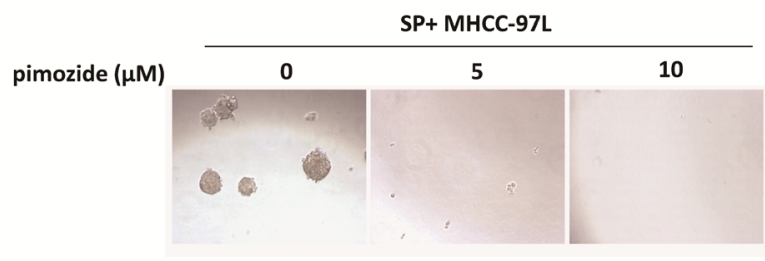

D

(a)

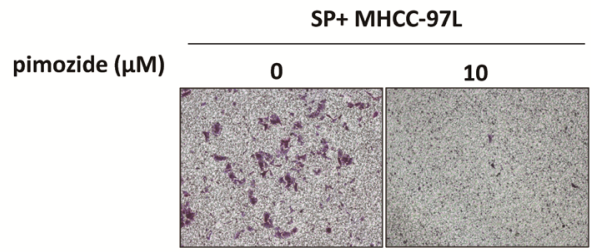

(b)

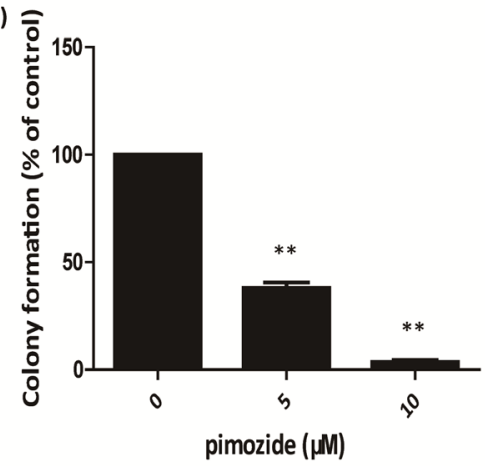

(b)

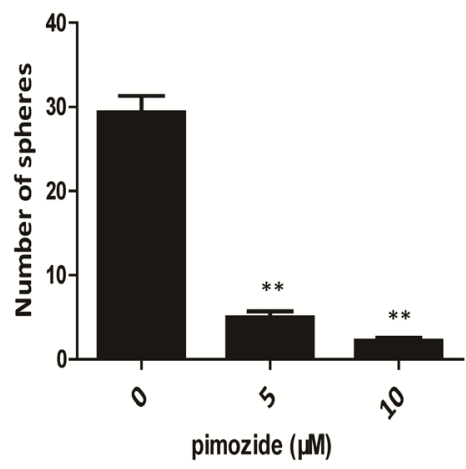

(b)

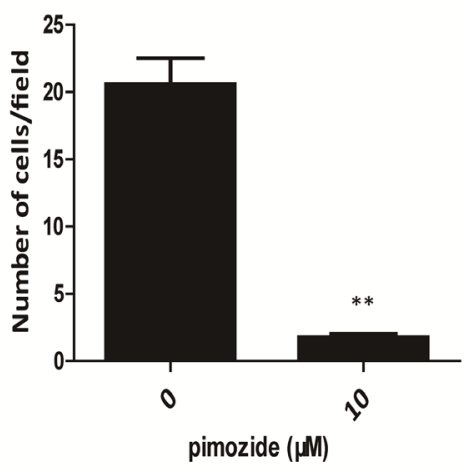

Figure 4: Pimozide inhibits the self-renewal and migration capacities of SP HCC cells. A. Fluorescence-activated cell sorting isolation of SP MHCC-97L cells. B. Colony formation assay of SP MHCC-97L cells treated with 5 $4 \mathrm{M}$ or $10 \mu \mathrm{M}$ pimozide. The images (a) and statistical results (b) are shown. C. Sphere formation assay of SP MHCC-97L cells treated with pimozide. D. Transwell migration assay of SP MHCC-97L cells treated with $10 \mu \mathrm{M}$ pimozide for $48 \mathrm{~h}$. Images are shown at a magnification of $100 \times$, and the statistical results are shown. The data are summarized from 3 independent experiments, ${ }^{*} p<0.05, * * p<0.01$, compared to the control. 


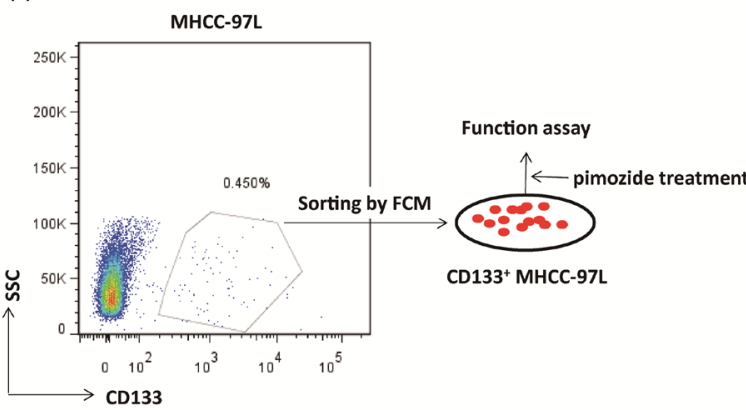

B (b)

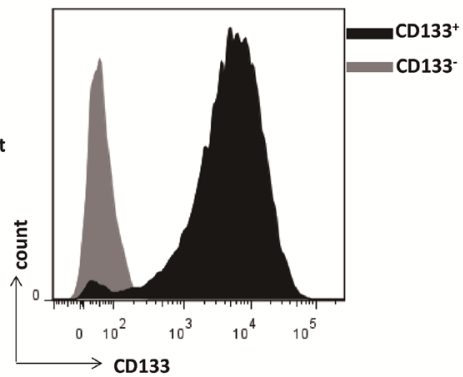

(b)

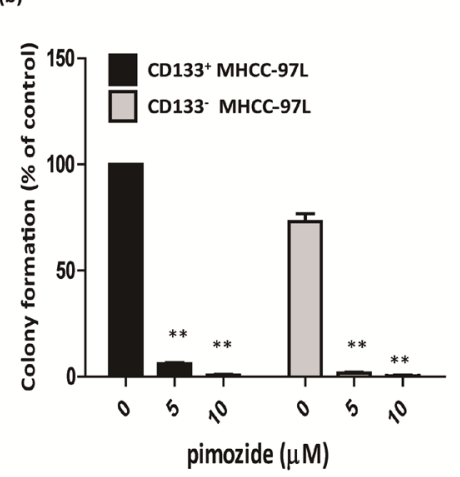

(b)

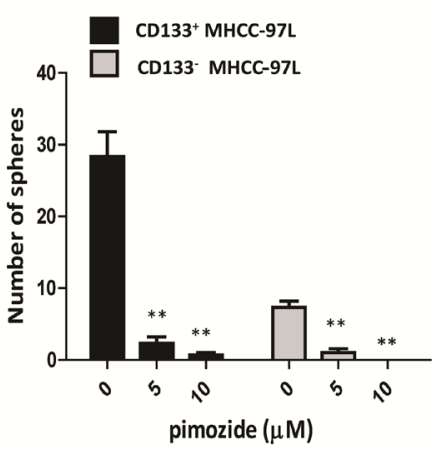

(b)

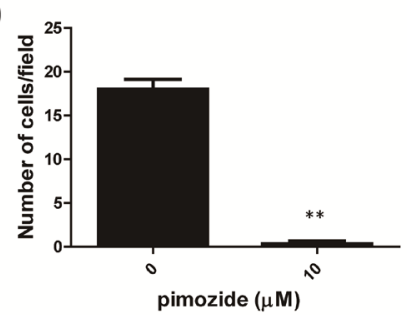

Figure 5: Pimozide inhibits the self-renewal and migration capacities of CD133-positive HCC cells. A. Fluorescenceactivated cell sorting isolation of CD133-positive cells and negative cells from MHCC-97L cells (a). The purity of fluorescence-activated cell sorting isolation was confirmed (b). B. Colony formation assay of CD133-positive and negative MHCC-97L cells treated with the indicated doses of pimozide. The images (a) and statistical results (b) are shown. C. Sphere formation assay of CD133-positive and negative MHCC-97L cells treated with pimozide. D. Transwell migration assay of CD133-positive MHCC-97L cells treated with $10 \mu \mathrm{M}$ pimozide for 24h. Images are shown at a magnification of $100 \times$, and the statistical results are shown. The data are summarized from 3 independent experiments, ${ }^{*} p<0.05,{ }^{* *} p<0.01$, compared to the control. 


\section{Pimozide suppresses STAT3 signaling and reverses cancer stem-like cell phenotypes induced by IL-6 addition in HCC cells}

Dysregulated STAT3 signalling has been strongly implicated in tumourigenesis through its effects on cell growth, angiogenesis, immune system evasion, and apoptosis prevention [31]. The activation of STAT3 signaling was reported to maintain the tumor-initiating ability in HCC cells, with high expression of STAT3 phosphorylation at tyrosine 705 [32]. The STAT3 phosphorylation in CD133-positive HCC cells or SP HCC cells were detected using Western blotting assay. Our results showed that CD133-positive cells or SP cells from MHCC-97L cells had high expression of phosphorylated STAT3 (Tyr705) and downstream gene c-Myc (Supplemental Figure 1C), indicating that in stemlike cells of HCC STAT3 signalling was fully activated.

Using qRT-PCR, we found that pimozide treatment inhibited the transcriptional levels of the STAT3 signaling related downstream genes $c-M y c, B c l-x L$ and $\mathrm{Mcl}-1$ (Figure 6A). In addition, pimozide reduced phosphorylation of STAT3 (Tyr705) expression in both MHCC-97L and Hep 3B cells in a dose-dependent manner (Figure 6B). Furthermore, pimozide inhibited STAT3-dependent luciferase activity in a dose-dependent manner (Figure 6C). IL-6 exerts many functions via the activation of STAT3 signaling in HCC cells, showing high expression of STAT3 phosphorylation at tyrosine 705 and at serine 727 [33]. Western blot analysis showed that IL-6 activated STAT3 signaling in MHCC-97L cells with high level of phosphorylated STAT3 (Y705), phosphorylated STAT3 (S727) and c-Myc expression (Figure 6D). However, pimozide treatment rescued the phosphorylation expression of STAT3 at the sites of both Tyr 705 and Ser 727 , as well as reduced the downstream c-Myc expression induced by IL-6 addition (Figure 6D).

Moreover, we examined whether pimozide reversed the phenotypes of cancer stem-like cells induced by IL-6 treatment in HCC cells. Functional assays showed that IL-6 treatment significantly enhanced the self-renewal and migration capacities, as evaluated by in vitro colony formation, sphere formation and transwell migration assays in MHCC-97L cells, suggesting that IL-6 addition could enhance the stemness of HCC cells (Figure 6D-6G). In contrast, pimozide could reverse the IL-6-induced selfrenewal and migration capacities of these cells (Figure 6D-6G), further suggesting that pimozide inhibited STAT3 signaling activity to suppress stem-like cell maintenance and tumorigenicity in $\mathrm{HCC}$ cells.

\section{Pimozide reduces the tumour burden in a nude mouse HCC-xenograft model}

Since pimozide reduced cell viability by inhibiting proliferation and self-renewal in cellular models, we next examined the effect of pimozide in a nude mice xenograft model. MHCC-97L hepatic cancer cells were injected subcutaneously into immunodeficient nude mice. Treatment with pimozide reduced the tumor burden to a level comparable to that of the control group, as assessed by tumor volume (Figure 7A and 7B). Furthermore, both treatments were well tolerated, with no significant effects on body weight (Figure 7C). These data indicated that the neuroleptic drug pimozide had anti-tumor efficacy in vivo without overt toxicity.

\section{DISCUSSION}

In recent years, increasing numbers of biotechnology companies have focused on drug repurposing, which is the development of novel uses for existing drugs [34]. Many existing drugs, such as metformin and disulfiram, have demonstrated anti-cancer effects in addition to their original uses. Compared with other types of cancer, HCC may benefit more from drug repurposing due to its poor prognosis and lack of effective chemotherapeutic agents [35].

Pimozide is an FDA-approved neuroleptic drug in clinical use. Due to its advantages of relatively low side effects and high clinical safety, pimozide has been used to treat other diseases in addition to central nervous system (CNS) diseases. During the past 20 years, pimozide has been found to be efficacious in treating monosymptomatic hypochondriacal psychoses, body dysmorphic disorder, metastatic melanoma, trichotillomania, as well as trigeminal and postherpetic neuralgia [36]. This study is the first to report that pimozide could be used as a new anti-cancer drug for treating HCC.

In our present study, we found that pimozide inhibited liver cancer cell proliferation and sphere formation by inducing G0/G1 phase cell cycle arrest. Previous studies have demonstrated that HCC cancer stem/stem-like cells are not targeted by current systemic chemotherapies and appear to be resistant to the conventional chemotherapeutic agents Cis, 5-FU and Dox $[28,37]$. For example, the SP fraction of the HCC cell line MHCC-97L was found to be refractory to the drug DOX [28]. Furthermore, CD133-positive hepatic cancer cells are resistant to conventional chemotherapeutic agents (5FU and DOX) [38]. In this study, MTT assay showed that CD133 positive cells or SP cells form MHCC-97L were respectively resistant to 5-FU, Cis and Dox, compared with their control cells (Supplemental Figure 1A and 1B). To our surprise, we found that pimozide significantly inhibited the colony formation,sphere formation and cell migration abilities of SP or CD133-positive HCC cells. Down-regulated expression of the stemness genes Bmi1, c-Myc and Nanog was also detected, which indicated that pimozide inhibited the self-renewal capacity of HCC cancer stem-like cells and might be preferable to conventional chemotherapy for targeting liver cancer stem/stem-like cells. 
A
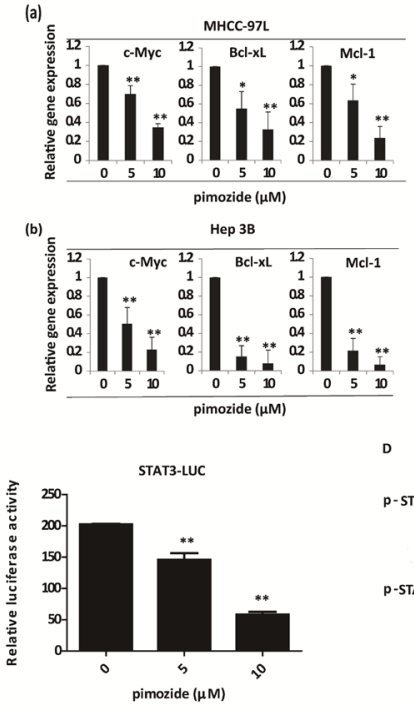

E (a)

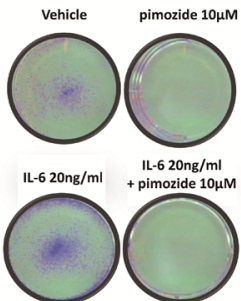

(a)

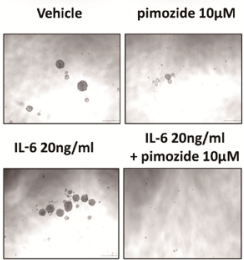

G (a)

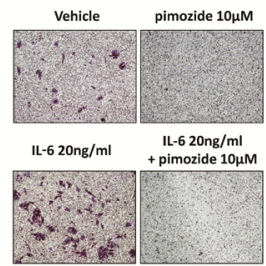

B (a) (a) MHCC-97L

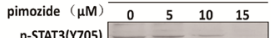

STAT3

GAPDH

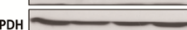

(b) Нер 3B $\begin{array}{cllll}\text { pimozide }(\mu M) & 0 & 5 & 10 & 15 \\ \text { p-STAT3(Y705) } & & & & \end{array}$

SAAT3

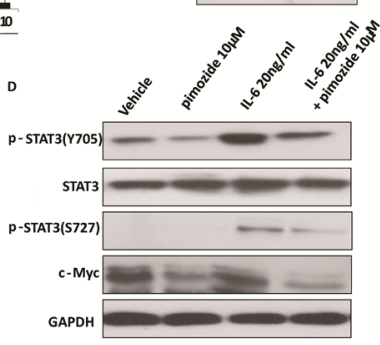

(b)
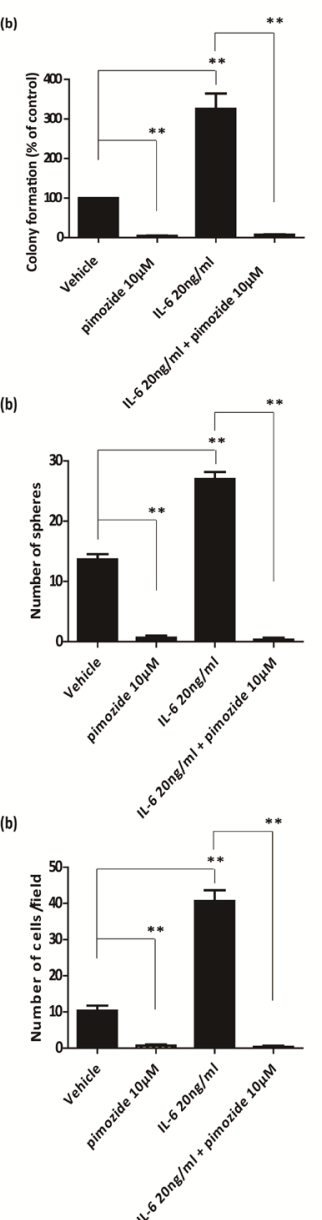

Figure 6: Pimozide suppresses the activity of STAT3 signaling and reverses cancer stem-like cell phenotypes induced by IL-6 addition in HCC cells. A. MHCC-97L and Hep 3B cells were incubated with the different doses of pimozide for 48h before subjected to RT-PCR to analyse the expression of the STAT3 downstream genes $c-M y c, B c l-x L$ and $M c l-1$. B. Western blot analysis of the expression of phosphorylated STAT3 (p-STAT3 Y705), STAT3 and c-Myc. C. HEK293T cells were transfected with STAT3 reporter and pRL-TK renilla luciferase reporter plasmids. After 24 hours of transfection, the cells were treated with different doses of pimozide for another $48 \mathrm{~h}$. Dual luciferase assay was performed to detect the relative luciferase activity. MHCC-97L cells were treated with 20

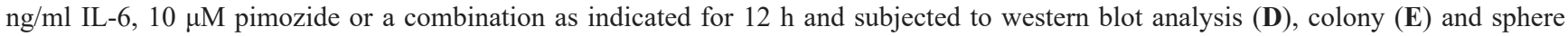
(F) formation assays, and transwell migration assay $(\mathbf{G})$ Relative representative figures are shown. The data are summarized from 3 independent experiments, ${ }^{*} p<0.05, * * p<0.01$. 
A

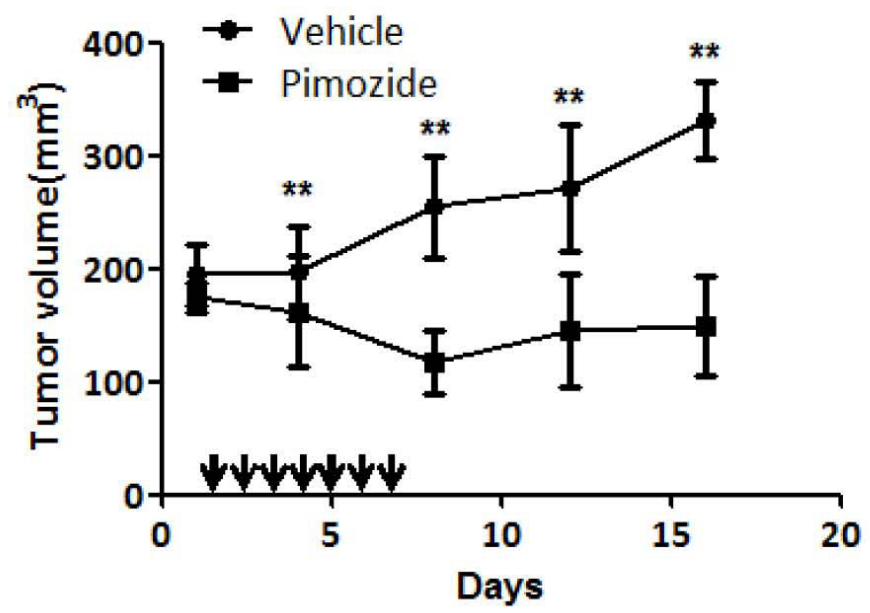

B

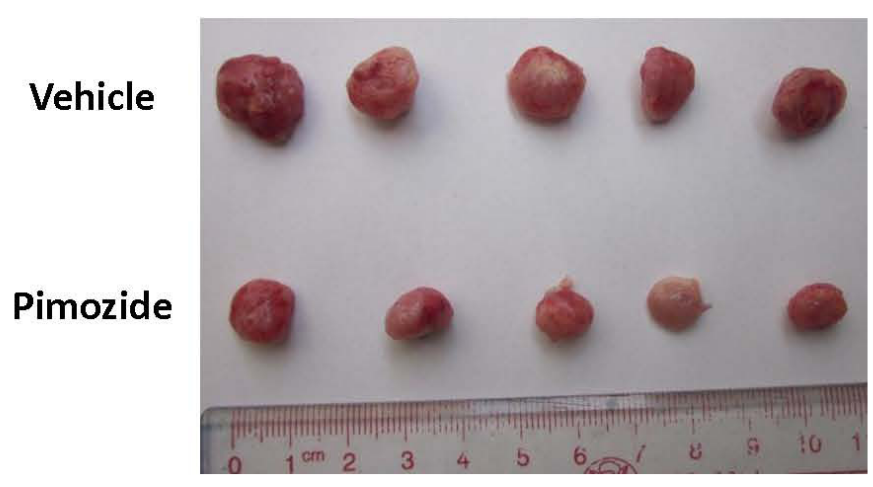

C

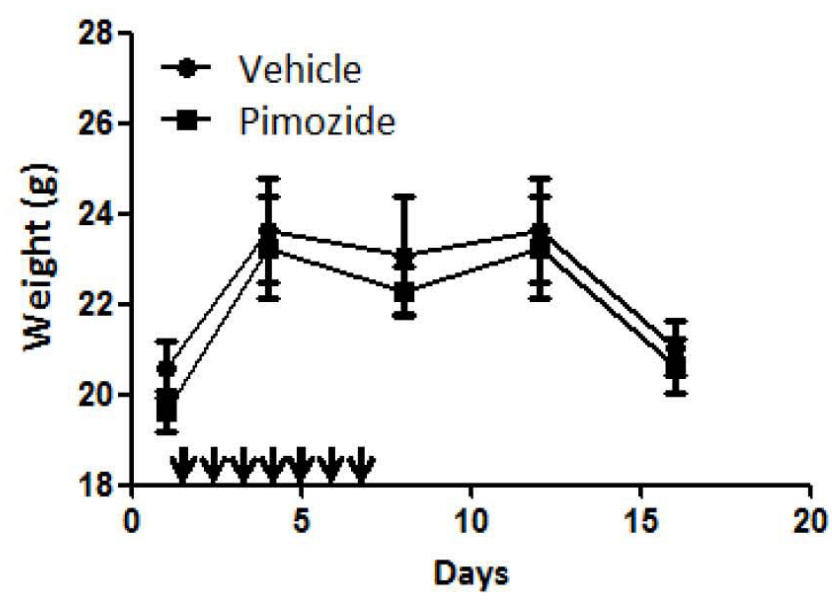

Figure 7: Pimozide reduces the tumor burden in a nude mice xenograft model. Pimozide was administered to mice previously injected with MHCC-97L cells. A. The tumour volume was measured and analysed at the indicated time points. Points, mean; bars, SE, ${ }^{* *} p$ $<0.01$. B. Representative tumors removed from mice of each group are shown. C. Body weights were determined for the animals in each treatment group. Points, mean; bars, SE. 
To delineate the underlying mechanism of the anti-cancer effect of pimozide on HCC cells, we tested select classical pathways involved in HCC carcinogenesis and found that the STAT3 pathway was significantly suppressed after pimozide treatment. As an oncogene, STAT3 is constitutively activated by the phosphorylation of Tyr705 in various human malignancies [31]. STAT3 is involved in oncogenesis, cell proliferation, angiogenesis, self-renewal and drug resistance. Phosphorylated STAT3 dimerizes and translocates into the nucleus for binding to specific DNA response elements to induce the transcription of downstream genes, such as $B C L-x L, M C L 1$, and $c-M y c$ [39]. Accumulating evidence has shown that of the inhibition of STAT3 activity in cancer cells can inhibit tumor growth and enhance chemotherapy sensitivity in $\mathrm{HCC}$ cells $[40,41]$. In addition, several clinical studies have reported that STAT3 signaling activation is associated with poor prognosis in HCC patients [42, 43]. Thus, targeting the STAT3 pathway using specific inhibitors may be a useful cancer treatment strategy with the potential for broad clinical application. The Janus kinase 2 inhibitor AG490 can abrogate the activation of constitutive STAT3 to inhibit growth and metastasis, and overcome drug resistance in human HCC cells [44]. In addition, sorafenib, a first-line therapy in treating patients with advanced liver cancer, demonstrats anti-tumor activity through the inhibition of STAT3 signaling [45]. Several other chemicals have also shown anti-cancer activity in treating HCC cells through the inhibition of STAT3 signaling $[46,47]$. In the present study, pimozide inhibited STAT3 phosphorylation and STAT3-dependent luciferase activity, and down-regulated the transcription levels of STAT3 signaling downstream genes $B C L-x L$, $M C L 1$, and $c-M y c$, significantly indicating that pimozide targeted STAT3 signaling.

IL-6 induces STAT3 phosphorylation at Tyr-705 and Ser-727 through IL-6 receptors and JAK to activate STAT3 signalling in HCC cells. IL-6/STAT3 signaling promotes survival, anti-apoptosis, migration, drug resistance and self-renewal [48]. Likewise, our data showed that pimozide decreased IL6-mediated STAT3 phosphorylation and could reverse cancer stem-like cell phenotypes induced by IL-6 addition in HCC cells, further suggesting that pimozide may be a potential agent for treating HCC cells by inhibiting STAT3 signaling and suppressing cancer stem-like cell maintenance. Besides, since pimozide is a well-known antagonist of serotonin 5-hydroxytryptamine receptor 7 (5HT7), which was overexpressed in human hepatocellular cancer (Data not shown, [49]), whether 5HT7 expression is associated with STAT3 activation in HCC cells is required to investigated in future.

Although pimozide causes cardiac toxicity, it has not been shown to have adverse effects on other normal functional cells, such as hepatic or haematopoietic cells. A previous study shows that pimozide decreases the colony formation ability of bone marrow progenitor cells derived from patients with CML. However, pimozide has almost no effect on haematopoietic progenitors derived from healthy donors [24]. Furthermore, pimozide treatments are well tolerated, with no significant effects on body weight in a mouse model [24]. Similar results were observed in our study. Additionally, according to the previous study, the precise lethal dose of pimozide in humans is unknown. The oral LD50 is $228 \mathrm{mg} / \mathrm{kg}$ in mice, $5120 \mathrm{mg} /$ $\mathrm{kg}$ in rats, $188 \mathrm{mg} / \mathrm{kg}$ in guinea pigs, and $40 \mathrm{mg} / \mathrm{kg}$ in dogs (DrugBank: Pimozide (DB01100) [50]). The dose of pimozide $(25 \mathrm{mg} / \mathrm{kg})$ used in our research is relatively lower compared to the commonly used dose for treating CNS disease. Therefore, pimozide may also be a safe drug for treating HCC.

In conclusion, this study demonstrates that the neuroleptic drug pimozide displays anti-tumour activity against HCC cells or stem-like cells and may be a novel candidate drug for treating advanced HCC. Of note, the development of new pimozide derivatives with stronger anti-cancer effects but lower side effects are urgently needed for advanced HCC [51].

\section{MATERIALS AND METHODS}

\section{Cell lines and cell culture}

The human HCC cell lines MHCC-97L and MHCC-97H (purchased from the Liver Cancer Institute, Zhongshan Hospital, Fudan University, Shanghai, China), HEK293T, Huh7 (provided by the Shanghai Cell Collection, Chinese Academy of Sciences, Shanghai, China), Hep 3B, and Hep G2 (purchased from American Type Culture Collection, Manassas, VA, USA) were cultured in Dulbecco's modified Eagle's medium (DMEM; Gibco, Grand Island, NY, USA) containing 10\% fetal bovine serum (FBS; Sigma, St. Louis, MO, USA). All media were supplemented with 100 units $/ \mathrm{ml}$ penicillin and $100 \mu \mathrm{g} / \mathrm{ml}$ streptomycin. All cell lines were kept at $37^{\circ} \mathrm{C}$ in a $5 \% \mathrm{CO}_{2}$ humidified atmosphere.

\section{Cell proliferation assay using MTT and CFSE staining}

Cell proliferation was evaluated by MTT assay according to the manufacturer's instructions. The human HCC cell lines MHCC-97L, Hep 3B, Hep G2 and Huh7 were seeded in 96-well culture plates with 2,000 cells per well. Subsequently, the cells were treated with pimozide at different concentrations for various time intervals $(24 \mathrm{~h}$, $48 \mathrm{~h}$ and $72 \mathrm{~h}$ ). The cells were incubated for another $4 \mathrm{~h}$ at $37^{\circ} \mathrm{C}$ after $20 \mu \mathrm{L}$ MTT $(5 \mathrm{mg} / \mathrm{ml})$ solution was added to each well. The supernatant fluid was removed, and $150 \mu \mathrm{L}$ DMSO was added to each well. The absorbance at $490 \mathrm{~nm}$ 
was finally measured using a microplate reader (BioTek, Vermont, USA).

To provide a direct measure of cell proliferation, 5- or 6-(N-succinimidyloxycarbonyl)-3,6-O,Odiacetylfluorescein (CFSE, Sigma, St. Louis, MO, USA) staining was also used for flow cytometric analysis of cells treated with pimozide for $48 \mathrm{~h}$ according to the manufacturer's instructions.

\section{Cell cycle assay}

Cell cycle distribution was determined by propidium iodide (PI, Sigma, St. Louis, MO, USA) staining and flow cytometric analysis according to the manufacturer's instructions. Briefly, equal amounts of cells were seeded in 6-well plates and treated with pimozide at different concentrations for $48 \mathrm{~h}$. After suspended in cold absolute ethanol, the cells were washed with PBS containing $0.1 \%$ BSA and stained with PI buffer $(40 \mu \mathrm{g} / \mathrm{mL}$ containing 100 $\mu \mathrm{g} / \mathrm{mL}$ RNase) for $30 \mathrm{~min}$ before flow cytometric analysis.

\section{Colony formation assay}

Cells that underwent different drug treatments were plated in $10 \%$ FBS medium. After incubation for 10-14 days, the cells were washed with ice-cold PBS, fixed with $20 \%$ methanol, and stained with $0.5 \%$ crystal violet. The morphology of colonies was imaged under a stereomicroscope. The colony is defined as a cluster of at least 50 cells. The numbers of colonies were counted.

\section{Sphere formation assay}

The sphere formation assay was performed as described previously [26]. To establish sphere cultures, single cells were cultured in $200 \mu \mathrm{l}$ serum-free DMEM/ F12 medium (Gibco) supplemented with $20 \mathrm{ng} / \mathrm{ml}$ human recombinant epidermal growth factor (EGF, PeproTech), $20 \mathrm{ng} / \mathrm{ml}$ human recombinant basic fibroblast growth factor (bFGF, PeproTech), and B27 (1:50; Gibco). The cells were cultured at a density of $5 \times 10^{2}$ cells/well in ultra-low attachment plates with different treatments for 7 days, and all of the spheres in each well were imaged.

\section{Transwell migration assay}

For this assay, $1 \times 10^{5}$ cells in serum-free medium were seeded in the upper compartment of a Transwell chamber (Corning, NY, USA) with different doses of pimozide. After the cells were incubated with pimozide for $48 \mathrm{~h}$, the migrated cells on the lower membrane were stained with $0.1 \%$ crystal violet and then counted.

\section{Sorting of HCC stem-like cells}

HCC stem-like cells were collected for functional assays using SP cells or CD133-positive cells from the MHCC-97L cell line sorted by flow cytometry.

The SP analysis procedures were based on a previously described protocol [27]. Briefly, the cells were trypsinized and suspended in DMEM with $2 \%$ FBS and $10 \mathrm{mM}$ HEPES buffer. Next, the cells were stained for $90 \mathrm{~min}$ with $5 \mu \mathrm{g} / \mathrm{ml}$ Hoechst 33342 dye (Invitrogen, USA) in the presence or absence of $50 \mu \mathrm{M}$ verapamil. The incubation was performed with shaking at intervals. After the cells were incubated, they were resuspended in icecold PBS containing $2 \mu \mathrm{g} / \mathrm{ml}$ PI. Flow cytometric analysis was performed using a MoFlo XDP cell sorter (Beckman Coulter, Fullerton, CA). The SP gate was defined as the diminished area on the dot plot in the presence of verapamil. The SP MHCC-97L cells were used to evaluate the effects of pimozide.

The CD133-positive population in the MHCC-97L cell line was sorted by flow cytometry using a MoFlo XDP cell sorter (Beckman Coulter, Fullerton, CA). The cells were stained with PE-conjugated anti-human CD133/1 (clone AC133-MAC, Miltenyi Biotec, Auburn, CA, USA). Isotype-matched mouse immunoglobulins served as controls. The CD133-positive cells in the MHCC-97L cell line were used for further functional analysis.

\section{Western blotting}

Equal amounts of protein from each sample were subjected to SDS-PAGE and then transferred to nitrocellulose membranes (Merck Millipore, Billerica MA, USA). The blots were incubated with primary antibodies against GAPDH (Ambion, Austin, TX, USA), p21, Bmi1, Nanog, E-cadherin, N-cadherin, vimentin, phosphoSTAT3 (p-STAT3(Ser727) and p-STAT3(Tyr705)), STAT3 (Cell Signaling Technology Corp, Beverly, MA, USA), p27, cyclin D1, c-Myc, Oct3/4 and $\beta$-actin (Santa Cruz Biotechnology, Santa Cruz, CA, USA). Antibody binding was detected using an enhanced chemiluminescence kit (Sigma, St. Louis, MO, USA).

\section{STAT3 luciferase reporter assay}

Transient transfections were conducted using Lipofectamine 2000 (Invitrogen, USA) according to the manufacturer's instructions. For the luciferase reporter assay, HEK293T cells were seeded in 24-well plates and transfected with the STAT3 luciferase reporter plasmid STAT3-Luc (pGL3.0, Promega, USA). The cells were collected $48 \mathrm{~h}$ after transfection, and the luciferase activities in the cell lysates were determined using the Dual Luciferase Reporter Assay System (Promega, WI, 
USA). Each transfection was performed in triplicate and repeated at least three times.

\section{RNA isolation and real-time PCR}

RNA was extracted using TRIzol (Invitrogen) according to the manufacturer's protocol and reversely transcribed into cDNA using a Revert Aid First-Strand cDNA Synthesis Kit (Thermo Scientific, USA). The primers are provided in Supplemental Table 1. GAPDH expression was used as an internal control.

\section{In vivo tumorigenicity experiments}

MHCC-97L cells were resuspended in PBS, and then $5 \times 10^{6}$ cells were injected subcutaneously into 8-week-old male nude mice (BALB/C, nu/nu). A small tumour formed a week after the tumor cell inoculation, and mice with established disease were divided into cohorts ( $n=5$ per group) with matched tumour burdens. Mice were treated with either $25 \mathrm{mg} / \mathrm{kg}$ pimozide in PEG2000 (Sigma, St. Louis, MO) by oral gavage (PO) or a vehicle at the same volume PO. The treatments were administered continuously for 7 days. The tumor volumes and body weights were determined at different times. All studies involving mice were performed according to protocols approved by the Animal Care and Use Committee of The Third Affiliated Hospital of Sun Yat-sen University.

\section{Statistical analysis}

The data, which are presented as the mean $\pm \mathrm{SD}$, were analysed using GraphPad Prism 6.0 (GraphPad Software, Inc.). Student's t-test was used to compare the differences between two groups. The level of significance was set at $p<0.05$.

\section{ACKNOWLEDGMENTS}

We thank the members of Qi Zhang lab and Organ Transplantation Center, The Third Affiliated Hospital, Sun Yat-sen University for their critical comments. We also thank Dr. Bin He (Cancer center, Sun Yat-sen University) for his technical support of flow cytometric sorting.

\section{CONFLICTS OF INTEREST}

The authors have declared that no competing interests exist.

\section{Author contributions}

Conceived and designed the study: CJJ, ZQ. Analyzed the data: CJJ, CN, CGZ, JCC. Performed the studies: CJJ, CN, CGZ, JCC, QDB, CGZ, DC, LW. Contributed reagents /materials/analysis tools: YY, ZQ. Wrote the manuscript: CJJ, CN, LZJ, ZQ.

\section{GRANT SUPPORT}

This work was supported by: China Postdoctoral Science Foundation funded project (2014M562239 to J.-J. Chen), National Natural Science Foundation of China (81370555 to Q Zhang), National Natural Science Foundation of Guangdong Province (S20120011190 to Q Zhang), 985 Project (82000-3281901), Fundamental Research Funds for the Central Universities (10ykpy05), as well as State Key Projects on Infection Diseases of China (2012ZX10002016-023, 2012ZX10002010-001007).

\section{REFERENCES}

1. Boguski MS, Mandl KD and Sukhatme VP. Drug discovery. Repurposing with a difference. Science. 2009; 324(5933): 1394-1395.

2. Carley DW. Drug repurposing: identify, develop and commercialize new uses for existing or abandoned drugs. Part I. IDrugs. 2005; 8: 306-309.

3. Carley DW. Drug repurposing: identify, develop and commercialize new uses for existing or abandoned drugs. Part II. IDrugs. 2005; 8: 310-313.

4. Blatt J and Corey SJ. Drug repurposing in pediatrics and pediatric hematology oncology. Drug Discov Today. 2013; 18: 4-10.

5. Kasznicki J, Sliwinska A and Drzewoski J. Metformin in cancer prevention and therapy. Ann Transl Med. 2014; 2: 57.

6. Del Barco S, Vazquez-Martin A, Cufí S, Oliveras-Ferraros C, Bosch-Barrera J, Joven J, Martin-Castillo B and Menendez JA. Metformin: Multi-faceted protection against cancer. Oncotarget. 2011; 2: 896-917.

7. Triscott J, Lee C, Hu K, Fotovati A, Berns R, Pambid M, Luk M, Kast RE, Kong E, Toyota E, Yip S, Toyota B and Dunn SE. Disulfiram, a drug widely used to control alcoholism, suppresses self-renewal of glioblastoma and overrides resistance to temozolomide. Oncotarget. 2012; 3: $1112-1123$.

8. Fishman MC and Porter JA. Pharmaceuticals: a new grammar for drug discovery. Nature. 2005; 437: 491-493.

9. Saponara M, Pantaleo MA, Nannini M and Biasco G. Treatments for gastrointestinal stromal tumors that are resistant to standard therapies. Future Oncol. 2014; 10: 2045-2059.

10. Kelley RK, Hwang J, Magbanua MJ, Watt L, Beumer JH, Christner SM, Baruchel S, Wu B, Fong L, Yeh BM, Moore AP, Ko AH, Korn WM, Rajpal S, Park JW, Tempero MA, Venook AP and Bergsland EK. A phase 1 trial of imatinib, bevacizumab, and metronomic cyclophosphamide in 
advanced colorectal cancer. Br J Cancer. 2013; 109: 17251734.

11. Ana Maria C and Catherine F. Current Management of Hepatocellular Carcinoma. Gastroenterol Hepatol (NY). 2014; 10: 153-161.

12. Hoshida Y, Fuchs BC and Tanabe KK. Prevention of hepatocellular carcinoma: potential targets, experimental models, and clinical challenges. Current cancer drug targets. 2012; 12: 1129-1159.

13. Altekruse SF, McGlynn KA and Reichman ME. Hepatocellular carcinoma incidence, mortality, and survival trends in the United States from 1975 to 2005. J Clin Oncol. 2009; 27: 1485-1491.

14. Lopa M, Tanuj B, Joseph M, Stephen B, Arun T, Aiwu RH, Kirti S, Lynt J and E. P. Reddy. Liver Stem Cells and Hepatocellular Carcinoma. Hepatology. Hepatology. 2009; 49: 318-329.

15. Ji JF and Wang XW. Clinical Implications of Cancer Stem Cell Biology in Hepatocellular Carcinoma. Semin Oncol. 2012; 39: 461-472.

16. Seung KY. The Biology of Cancer Stem Cells and Its Clinical Implication in Hepatocellular Carcinoma. Gut Liver. 2012; 6: 29-40.

17. Roskams T. Liver stem cells and their implication in hepatocellular and cholangiocarcinoma. Oncogene. 2006; 25: $3818-3822$.

18. Caecilia HS, Natalia R, Lory SC and Claudio T. Hepatic cancer stem cells and drug resistance: Relevance in targeted therapies for hepatocellular carcinoma. World J Hepatol. 2010; 2: 114-126.

19. Melchiorre C, James AM, Antonella C, Nadia L, Antonina A and Giuseppe M. Targeted therapy for hepatocellular carcinoma: novel agents on the horizon. Oncotarget. 2012; 3: 236-260.

20. Egolf A and Coffey BJ. Current pharmacotherapeutic approaches for the treatment of Tourette syndrome. Drugs Today (Barc). 2014; 50: 159-179.

21. Taub RN and Baker MA. Treatment of metastatic malignant melanoma with pimozide. Lancet. 1979; 1: 605.

22. Strobl JS, Kirkwood KL, Lantz TK, Lewine MA, Peterson VA and Worley JF. Inhibition of human breast cancer cell proliferation in tissue culture by the neuroleptic agents pimozide and thioridazine. Cancer Res. 1990; 50: 53995405.

23. Nelson EA, Walker SR, Weisberg E, Bar-Natan M, Barrett R, Gashin LB, Terrell S, Klitgaard JL, Santo L, Addorio MR, Ebert BL, Griffin JD and Frank DA. The STAT5 inhibitor pimozide decreases survival of chronic myelogenous leukemia cells resistant to kinase inhibitors. Blood. 2011; 117: 3421-3429.

24. Nelson EA, Walker SR, Xiang M, Weisberg E, Bar-Natan M, Barrett R, Liu S, Kharbanda S, Christie AL, Nicolais M, Griffin JD, Stone RM, Kung AL and Frank DA. The STAT5 Inhibitor Pimozide Displays Efficacy in Models of
Acute Myelogenous Leukemia Driven by FLT3 Mutations. Genes Cancer. 2012; 3: 503-511.

25. Strobl JS, Melkoumian Z, Peterson VA and Hylton H. The cell death response to gamma-radiation in MCF-7 cells is enhanced by a neuroleptic drug, pimozide. Breast Cancer Res Treat. 1998; 51: 83-95.

26. Levina V, Marrangoni AM, DeMarco R, Gorelik E, Lokshin AE. Drug-selected human lung cancer stem cells: cytokine network, tumorigenic and metastatic properties. PloS one. 2008; 3: e3077.

27. Chiba T, Kita K, Zheng YW, Yokosuka O, Saisho H, Iwama A, Nakauchi H and Taniguchi H. Side population purified from hepatocellular carcinoma cells harbors cancer stem cell-like properties. Hepatology. 2006; 44: 240-251.

28. Wu Q, Wang R, Yang Q, Hou X, Chen SL, Hou YY, Chen CJ, Yang Y, Miele L, Sarkar FH, Chen YQ and Wang ZW. Chemoresistance to gemcitabine in hepatoma cells induces epithelial-mesenchymal transition and involves activation of PDGF-D pathway. Oncotarget. 2013; 4: 1999-2009.

29. Hu C, Li H, Li JJ, Zhu Z, Yin SY, HaoXF, Yao M, Zheng $\mathrm{SS}$ and GuJR. Analysis of ABCG2 expression and side population identifies intrinsic drug efflux in the HCC cell line MHCC-97L and its modulation by Akt signaling. Carcinogenesis. 2008; 29: 2289-2297.

30. Song W, Li H, Tao K, Li R, Song Z, Zhao Q, Zhang F, Dou K. Expression and clinical significance of the stem cell marker CD133 in hepatocellular carcinoma. Int J Clin Pract. 2008; 62: 1212-1218.

31. Siddiquee KAZ and Turkson J. STAT3 as a target for inducing apoptosis in solid and hematological tumors. Cell research. 2008; 18: 254-267.

32. Yao Z and Mishra L. Cancer stem cells and hepatocellular carcinoma. Cancer biology \& therapy 2009; 8: 1691-1698.

33. Hodge DR, Hurt EM and Farrar WL. The role of IL- 6 and STAT3 in inflammation and cancer. Eur J Cancer. 2005; 41: 2502-2512.

34. Ashburn TT and Thor KB. Drug repositioning: identifying and developing new uses for existing drugs. Nat Rev Drug Discov. 2004; 3: 673-683.

35. Villanueva A and Llovet JM. Targeted Therapies for Hepatocellular Carcinoma. Gastroenterology. 2011; 140: 1410-1426.

36. Lorenzo CR and Koo J. Pimozide in dermatologic practice: a comprehensive review. Am J Clin Dermatol. 2004; 5: 339-349.

37. Ma S, Lee TK, Zheng BJ, Chan KW and Guan XY. CD133+ HCC cancer stem cells confer chemoresistance by preferential expression of the Akt/PKB survival pathway. Oncogene. 2008; 27: 1749-1758.

38. Yin, S., Li, J., Hu, C., Chen, X., Yao, M., Yan, M., Jiang, G., Ge, C., Xie, H., Wan, D., Yang, S., Zheng, S. and Gu, J. CD133 positive hepatocellular carcinoma cells possess high capacity for tumorigenicity. Int J Cancer. 2007; 120: 1444-1450. 
39. Yu H, Kortylewski M and Pardoll D. Crosstalk between cancer and immune cells: role of STAT3 in the tumour microenvironment. Nat Rev Immunol. 2007; 7: 41-51.

40. Wang X, Crowe PJ, Goldstein D and Yang JL. STAT3 inhibition, a novel approach to enhancing targeted therapy in human cancers (review). Int J Oncol. 2012; 41: 11811191.

41. Kusaba M, Nakao K, Goto T, Nishimura D, Kawashimo H, Shibata H, Motoyoshi Y, Taura N, Ichikawa T, Hamasaki $\mathrm{K}$ and Eguchi K. Abrogation of constitutive STAT3 activity sensitizes human hepatoma cells to TRAIL-mediated apoptosis. J Hepatol 2007; 47: 546-555.

42. Zhang CH, Xu GL, Jia WD, Li JS, Ma JL, Ren WH, Ge YS, Yu JH, Liu WB and Wang W. Activation of STAT3 signal pathway correlates with twist and E-cadherin expression in hepatocellular carcinoma and their clinical significance. J Surg Res. 2012; 174: 120-129.

43. Wu WY, Li J, Wu ZS, Zhang CL, Meng XL and Lobie PE. Prognostic significance of phosphorylated signal transducer and activator of transcription 3 and suppressor of cytokine signaling 3 expression in hepatocellular carcinoma. Exp Ther Med. 2011; 2: 647-653.

44. Fuke H, Shiraki K, Sugimoto K, Tanaka J, Beppu T, Yoneda K, Yamamoto N, Ito K, Masuya M and Takei Y. Jak inhibitor induces $\mathrm{S}$ phase cell-cycle arrest and augments TRAIL-induced apoptosis in human hepatocellular carcinoma cells. Biochem Biophys Res Commun. 2007; 363: 738-744.

45. Chen KF, Tai WT, Liu TH, Huang HP, Lin YC, Shiau CW, Li PK, Chen PJ and Cheng AL. Sorafenib overcomes TRAIL resistance of hepatocellular carcinoma cells through the inhibition of STAT3. Clin Cancer Res. 2010; 16: 51895199.
46. Deng P1, Wang C, Chen L, Wang C, Du Y, Yan X, Chen $\mathrm{M}$, Yang $\mathrm{G}$ and $\mathrm{He} \mathrm{G}$. Sesamin induces cell cycle arrest and apoptosis through the inhibition of signal transducer and activator of transcription 3 signalling in human hepatocellular carcinoma cell line HepG2. Biol Pharm Bull. 2013; 36: 1540-1548.

47. Song X, Wang J, Zheng T, Song R, Liang Y, Bhatta N, Yin D, Pan S, Liu J, Jiang H and Liu L. LBH589 Inhibits proliferation and metastasis of hepatocellular carcinoma via inhibition of gankyrin/STAT3/Akt pathway. Mol Cancer. 2013; $12: 114$.

48. Krishnamurthy S, Warner KA, Dong Z, Imai A, Nör C, Ward BB, Helman JI, Taichman RS, Bellile EL, McCauley LK, Polverini PJ, Prince ME, Wicha MS and Nör JE. Endothelial interleukin- 6 defines the tumorigenic potential of primary human cancer stem cells. Stem Cells. 2014; 32: 2845-2857.

49. Soll C, Riener MO, Oberkofler CE, Hellerbrand C, Wild PJ, DeOliveira ML and Clavien PA. Expression of serotonin receptors in human hepatocellular cancer. Clin Cancer Res. 2012; 18: 5902-5910.

50. Wishart DS, Knox C, Guo AC, Cheng D, Shrivastava S, Tzur D, Gautam B and Hassanali M. DrugBank: a knowledgebase for drugs, drug actions and drug targets. Nucleic Acids Res. 2008; 36: D901-D906.

51. Rondanin R, Simoni D, Romagnoli R, Baruchello R, Marchetti P, Costantini C, Fochi S, Padroni G, Grimaudo $\mathrm{S}$, Pipitone RM, Meli $\mathrm{M}$ and Tolomeo M. Inhibition of activated STAT5 in Bcr/Abl expressing leukemia cells with new pimozide derivatives. Bioorg Med Chem Lett. 2014; 24: 4568-4574. 